\title{
Native bumble bee (Hymenoptera: Apidae) pollinators vary in floral resource use across an invasion gradient
}

\author{
S.D. Gillespie, ${ }^{1}$ J. Bayley, E. Elle
}

\begin{abstract}
Integration of pollinator-dependent invasive plants into native pollination networks can have direct and indirect effects on local plant and pollinator communities. Impacts on local plants are well documented; however effects on native pollinators have gained less attention. We examine these issues in habitat fragments of the endangered oak-savannah ecosystem in British Columbia, Canada. We measured pollen collection by native bumble bees (Bombus Latreille; Hymenoptera: Apidae) and the introduced honey bee (Apis mellifera Linnaeus; Hymenoptera: Apidae) foraging on two common native plants in habitat fragments with varying invasive (Cytisus scoparius (Linnaeus) Link; Fabaceae) density. The Bombus species with the largest workers had higher proportions of invasive pollen on their bodies and in their corbiculae than smaller workers. Honey bees rarely collected $C$. scoparius pollen. While some native bumble bees species collect an increasing proportion of $C$. scoparius pollen with increasing C. scoparius density, this did not translate into an increased potential for pollination. Rather, measures of effective pollination decline with $C$. scoparius density. Overall, our results suggest that some bee species may be better at finding resources at highly invaded sites. Apis mellifera is likely not playing a major role in facilitating the spread of $C$. scoparius in our region. Rather $C$. scoparius is visited by a complement of native bumble bees that are similar to pollinators in the native range of this plant.
\end{abstract}

\section{Introduction}

Persistence of pollinator-dependent non-native plants after introduction depends on the invasive species being integrated into existing pollinator communities (Morales and Aizen 2006; Aizen et al. 2008; Pysek et al. 2011). This integration can have direct and indirect effects on native plants and pollinators. The impacts of invasive plants on native plant species are well documented: direct impacts can occur through resource competition (Pysek et al. 2012), indirect impacts via shared pollinators (Brown et al. 2002; King and Sargent 2012). For the latter, pollinator mediated effects can be negative, neutral, or positive (facilitative) depending on the impacts the invasive plant has on pollinator behaviour (Traveset and Richardson 2006, 2014).

The effects of pollinator-dependent invasive plants on native pollinators have gained less attention. Pollinator-dependent invasive plants tend to have generalist pollination strategies - where their floral rewards are accessible by a wide range of pollinator taxa - and abundant floral rewards (Traveset and Richardson 2014). They therefore provide plentiful resources for generalist native pollinators. By outcompeting flowering native plants and reducing local plant diversity (Shaben and Myers 2010; Pysek et al. 2012), flowering invasive plants could reduce habitat-level nutritional diversity or temporal continuity of resources for pollinators.

Furthermore, not all invasive plants have generalist pollination strategies (Johnson and Raguso 2016). A combination of restricted potential pollinators with displacement of native plants may exacerbate detrimental impacts on a subset of the pollinator community.

Pollinator and plant traits are both important for mediating the impacts of invasive plants on native pollinators. Insect pollinators such as bees (Hymenoptera: Apidae) need access to both nectar and pollen, while plants vary in the quantity of

Received 10 June 2016. Accepted 13 October 2016. First published online 6 January 2017.

S.D. Gillespie, ${ }^{1}$ J. Bayley, E. Elle, Evolutionary and Behavioural Ecology Research Group, Department of Biological Sciences, Simon Fraser University, Burnaby, British Columbia, V5A 1S6, Canada

${ }^{1}$ Corresponding author (e-mail: sgillesp@ @fu.ca).

Subject editor: Cory Sheffield

doi: $10.4039 /$ tce. 2016.67 
nectar and pollen provided. Generalist pollinators will forage on multiple plants in order to balance their nutritional needs (Harmon-Threatt and Kremen 2015; Vaudo et al. 2016). The types of rewards available from an invasive plant will thus mediate impacts on wild pollinators, such that a habitat dominated by an invasive plant species that provides only pollen may be less suitable for some pollinators. Pollinator species also vary in their ability to forage on different plant types. For example, tongue length or body size in bumble bees (Bombus Latreille; Hymenoptera: Apidae) can limit which flowers a particular species can forage on effectively (Inouye 1980; Goulson and Darvill 2004; Peat et al. 2005). However, not all invasive flowers have generalist pollination syndromes. In these cases, native pollinators that are able to use an invasive resource may be better able to persist at invaded sites, but could also have impacts on the persistence of the invasive. Native pollinator use of invasive plants can facilitate their reproduction, leading to increased invasive seed pressure (Montesinos et al. 2016). Alternately, in habitats where no effective native pollinators are present, introduced pollinators can play a role in facilitating the spread of invasive species. For example, the European honey bee, Apis mellifera Linnaeus (Hymenoptera: Apidae), facilitates the spread of some invasive plants in its introduced range (Stout et al. 2002; Simpson et al. 2005; Paynter et al. 2010).

Pollination of the invasive plant will also be affected by plant density. Many plants suffer reduced pollinator visits at low density (Kunin 1993). Furthermore, at lower invasive densities, other more attractive resources may be available, reducing visits to the invasive plant. This may have important implications for invasive plant management. For example, the presence of pollinators that visit an invasive even at low densities may mean that there is persistent seed pressure, even after invasive removal efforts.

We explored the impact of an invasive plant on native plants as mediated through pollinator behaviour in an oak-savannah ecosystem, endangered in southern British Columbia, Canada. This ecosystem hosts a highly diverse spring co-flowering community and is heavily affected by invasive plants (Fuchs 2004). Specifically, the invasive shrub Cytisus scoparius (Linnaeus) Link (Fabaceae) (scotch broom), has had a major impact on this ecosystem by displacing native plants and changing soil characteristics (Shaben and Myers 2010) but appears to have mixed effects on the pollination of native plants (Muir and Vamosi 2015). Cytisus scoparius is unusual among invasive species in that it requires pollinators to set seed and has a specialised pollination syndrome where only large bodied bees can open, or trip, the flowers to access pollen rewards and pollinate flowers (Parker 1997; Traveset and Richardson 2014). Cytisus scoparius also provides little to no nectar as a reward (Stout 2000). Furthermore, because many remnants of the oak-savannah ecosystem are situated within an urban/suburban matrix in British Columbia, visitation by the honey bees from nearby backyard beekeeper colonies is possible. In other parts of the invasive range of $C$. scoparius, honey bees are known to facilitate the spread of this plant (Simpson et al. 2005; Paynter et al. 2010), but the potential for honey bees to play this role in British Columbia is unknown. We examined the impact of this invasive plant on two common native wildflower species, Camassia quamash (Pursh) Greene, and C. leichtlinii (Baker) Watson (Asparagaceae) by quantifying pollen on the bodies of bumble bee and honey bee visitors to all three plant species.

We asked (1) whether different bee species caught on native Camassia Lindley and Cytisus scoparius were more likely to have previously foraged on invasive C. scoparius as it increases in density across sites; (2) whether those bees are incorporating $C$. scoparius pollen into nest provisions; (3) whether C. scoparius tripping rates, an indication of a potentially pollinating visit, change with $C$. scoparius density.

\section{Methods}

\section{Field methods}

Sites comprised 18 oak-savannah fragments in the greater Victoria area, British Columbia, Canada (Table 1). Sites were a minimum of $1.75 \mathrm{~km}$ apart. At each site, we delineated a 1-ha focal area encompassing populations of all our focal species, where present. At several sites this was split into two 1/2-ha patches, due to the steep rocky nature of the habitat. Sites varied in C. scoparius density primarily due to removal efforts by local volunteers and land managers. 
Table 1. Field site data.

\begin{tabular}{llcc}
\hline Park name & Manager & Latitude & Longitude \\
\hline Anderson Hill & City of Oak Bay & $48^{\circ} 24^{\prime} 45.66^{\prime} \mathrm{N}$ & $123^{\circ} 18^{\prime} 24.01^{\prime} \mathrm{W}$ \\
Beacon Hill & City of Victoria & $48^{\circ} 24^{\prime} 37.22^{\prime} \mathrm{N}$ & $123^{\circ} 21^{\prime} 42.60^{\prime} \mathrm{W}$ \\
Bear Hill & Capital Regional District & $48^{\circ} 32^{\prime} 44.59^{\prime} \mathrm{N}$ & $123^{\circ} 24^{\prime} 34.33^{\prime} \mathrm{W}$ \\
Cedar Hill & $48^{\circ} 27^{\prime} 29.80^{\prime} \mathrm{N}$ & $123^{\circ} 20^{\prime} 49.11^{\prime} \mathrm{W}$ \\
Gonzales Hill & District of Saanich & $48^{\circ} 24^{\prime} 51.60^{\prime} \mathrm{N}$ & $123^{\circ} 19^{\prime} 25.44^{\prime} \mathrm{W}$ \\
High Rock Cairn & Capital Regional District & $48^{\circ} 26^{\prime} 2.25^{\prime} \mathrm{N}$ & $123^{\circ} 24^{\prime} 24.69^{\prime} \mathrm{W}$ \\
Knockan Hill & City of Esquimalt & $48^{\circ} 28^{\prime} 12.83^{\prime} \mathrm{N}$ & $123^{\circ} 25^{\prime} 3.10^{\prime} \mathrm{W}$ \\
Konukson Park & District of Saanich & $48^{\circ} 27^{\prime} 18.61^{\prime} \mathrm{N}$ & $123^{\circ} 16^{\prime} 28.56^{\prime} \mathrm{W}$ \\
Layritz Park & District of Saanich & $48^{\circ} 29^{\prime} 25.73^{\prime} \mathrm{N}$ & $123^{\circ} 24^{\prime} 45.544^{\prime} \mathrm{W}$ \\
Little Saanich Mountain & District of Saanich & $48^{\circ} 31^{\prime} 9.22^{\prime} \mathrm{N}$ & $123^{\circ} 25^{\prime} 7.53^{\prime} \mathrm{W}$ \\
Mount Douglas & National Research Council of Canada & $48^{\circ} 29^{\prime} 33.41^{\prime} \mathrm{N}$ & $123^{\circ} 20^{\prime} 40.39^{\prime} \mathrm{W}$ \\
Mill Hill & District of Saanich & $48^{\circ} 27^{\prime} 15.36^{\prime} \mathrm{N}$ & $123^{\circ} 28^{\prime} 52.79^{\prime} \mathrm{W}$ \\
Mount Tolmie & Capital Regional District & $48^{\circ} 27^{\prime} 29.13^{\prime} \mathrm{N}$ & $123^{\circ} 19^{\prime} 26.46^{\prime} \mathrm{W}$ \\
Oak Haven & District of Saanich & $48^{\circ} 33^{\prime} 49.93^{\prime} \mathrm{N}$ & $123^{\circ} 26^{\prime} 48.49^{\prime} \mathrm{W}$ \\
Summit Park & Central Saanich & $48^{\circ} 26^{\prime} 38.58^{\prime} \mathrm{N}$ & $123^{\circ} 21^{\prime} 13.16^{\prime} \mathrm{W}$ \\
Thetis Lake & City of Victoria & $48^{\circ} 28^{\prime} 9.10^{\prime} \mathrm{N}$ & $123^{\circ} 27^{\prime} 59.12^{\prime} \mathrm{W}$ \\
Uplands Park & Capital Regional District & $48^{\circ} 26^{\prime} 29.13^{\prime} \mathrm{N}$ & $123^{\circ} 18^{\prime} 2.18^{\prime} \mathrm{W}$ \\
Christmas Hill & City of Oak Bay & $48^{\circ} 28^{\prime} 24.33^{\prime} \mathrm{N}$ & $123^{\circ} 22^{\prime} 38.62^{\prime} \mathrm{W}$ \\
\hline
\end{tabular}

At our sites, C. scoparius and both Camassia species have coinciding blooms occurring in late spring to early summer. Camassia leichtlinii and C. quamash have multiple blue to purple flowers on each stem that are easily accessible to all species of bees. Cytisus scoparius has hundreds of yellow pea-shaped flowers on a single bush with access to rewards limited to large bodied bees that can open (trip) the flowers.

We sampled sites five to six times over the course of $C$. quamash and C. leichtlinii bloom, late April through early June 2015. We divided sampling periods within a day into morning (10:00 AM-12:00 PM), midday (12:00-02:00 PM), and afternoon (02:00-04:00 PM) periods. Each site was sampled at least once for each period. We sampled between 10:00 AM and 04:00 PM, the peak of pollinator activity in the ecosystem, during pollinator appropriate weather (temperatures above $15^{\circ} \mathrm{C}$ and low winds). Two collectors sampled simultaneously for 20-minute periods, netting and euthanising any floral visitor and recording the species of flower visited. The collected bees were part of a larger pollinator interaction network study (by S.D.G. and E.E.). We focus on bumble bees (Bombus) and honey bees, as they were abundant pollinators in the sites that were caught on all focal plant species, and observed to be capable of tripping the flowers of $C$. scoparius (65\% of all insects netted on focal plants; $83 \%$ of insects caught on C. scoparius), thus we could attain a sufficient sample size. We sampled pollen from three native bumble bee species: Bombus melanopygus Nylander, B. mixtus Cresson, and B. vosnesenskii Radoszkowski, and from the introduced honey bee, A. mellifera.

The flowering community was quantified on each sampling date using four 50-m transects spaced $50 \mathrm{~m}$ apart in a stratified fashion throughout the sampling area. We sampled perpendicularly to the transect at random distances between $1-5 \mathrm{~m}$ using a $0.25 \times 2.0 \mathrm{~m}$ quadrat. Within each quadrat we counted the number of flowering units of each plant species. A flowering unit for both Camassia species was defined as a single flowering stem (C. quamash: average 1.97 open flowers, range $1-10 ; C$. leichtlinii: average 2.45 open flowers, range 1-11). For Cytisus scoparius, a unit was an individual branch on a bush with no further flowering branches arising from it (average 2.29 open flowers, range 1-10). To calculate C. scoparius and Camassia density, we summed the total number of stems of each species counted in our quadrats for each sampling date. For Camassia, we summed C. leichtlinii and C. quamash stem density, as we cannot differentiate their pollen under the microscope (see later). 
Finally, on each sampling date, we estimated the number of flowers "tripped" on C. scoparius. We defined a "tripped" flower as a flower with the keel depressed and the stamens and stigma exposed (Supplementary Figure 1). We selected two patches of $C$. scoparius - defined as a grouping of four or more plants. These were distributed across the sampling area as much as possible. Within each patch, we then randomly selected two shrubs, for a total of four shrubs per site per sampling date. On the closest stem, we counted the number of tripped and untripped flowers out of the first 25 encountered.

\section{Pollen sampling}

For each site, we collected pollen from the body and the corbiculae of 10 individuals of each bee species, five collected on Camassia, and five collected on C. scoparius. At some sites, a full sample of five bees per plant could not be obtained. Pollen from the body was collected by swabbing with a small piece of gelatin stained with fuschin dye (Kearns and Inouye 1993). Pollen from the corbiculae was homogenised with $300 \mu \mathrm{L}$ of ethanol and a $30-\mu \mathrm{L}$ subsample was placed on a slide, allowed to dry, then stained with fuschin dye. If a bee lacked corbicular pollen, only pollen from the body was sampled.

To sample pollen composition, we identified pollen grains under a microscope along two transects per slide using a marked coverslip. Pollen grains touching the transect were identified to the highest taxonomic resolution possible by comparison to a reference collection. We counted a maximum of 50 grains/transect, totalling 100 grains/sample. If a minimum of 50 grains/sample was not reached after two transects, an additional transect was added. The pollen of $C$. leichtlinii and $C$. quamash are indistinguishable, and will hereafter be referred to collectively as Camassia. Cytisus scoparius pollen is highly distinct and easily identified. Other pollen grains were identified to species where possible, and family if not. While many groups are difficult to differentiate to species, we are confident in our identification of Camassia and C. scoparius because of their distinct pollen. Because there was some variation in total pollen grains available to count, we calculated the ratio of $C$. scoparius to pollen grains in each pollen sample, as follows: $C$. scoparius grains/(C. scoparius +Camassia $)$, where the scale from 0 to 1 describes a gradient from mostly Camassia to mostly C. scoparius pollen in the sample. This means that pollen from other species were not part of the analysis; however, on average C. scoparius and Camassia pollen accounted for over $85 \%$ of pollen in each sample. Removal of samples with low quantities of either of our focal pollen type did not qualitatively change our results.

\section{Bumble bee worker size}

Because the size of bees can affect their ability to trip C. scoparius flowers, we measured body size of our sampled workers. We measured their intertegular span using microcalipers under a dissecting microscope. Intertegular span, or the shortest distance between the tegulae on the thorax, is a common measurement used to quantify body size in pollinators (Cane 1987). Honey bee measurements are based on 20 workers collected in previous pollinator studies on Vancouver Island, British Columbia, Canada (Chamberlain et al. 2014).

\section{Analysis}

All analyses were conducted in R ( $\mathrm{R}$ Development Core Team 2009). For bees collected on Camassia, we used general linear models, and type III sums of squares to test whether the species of Camassia from which the bee was collected (C. quamash or C. leichtlinii), sampling date, bee species identity, $C$. scoparius density, or the interaction between $C$. scoparius density and bee species had an effect on the ratio of $C$. scoparius to Camassia pollen (lmer, lme4 package for $\mathrm{R}$ (Bates et al. 2015)). Site was included as a random factor. We conducted separate analyses for corbicular and body pollen.

For individuals collected on C. scoparius, there was insufficient variation in pollen content to analyse pollen composition as a continuous variable. Therefore we categorised the pollen composition of our samples as either "pure" C. scoparius or Camassia pollen (>95) or mixed. We then used Fisher's exact test to determine whether the number of bees in each category varied among bee species for body or corbicular samples (R Development Core Team 2009). We excluded $B$. vosnesenskii from this analysis, as only two bees of this species were caught on C. scoparius. 
To examine how $C$. scoparius density affected C. scoparius pollination, we used similar models to those for Camassia-collected bees to test whether sampling date or C. scoparius density had an effect on the proportion of flowers tripped (lmer, lme4 package (Bates et al. 2015)). Site was included as a random factor.

\section{Results}

A total of 329 individuals of the focal species were sampled from those netted. We randomly subsampled at sites where more than 10 of a focal bee were collected on a focal plant. Of these bees, 240 had corbicular pollen loads that could be sampled. Of the bees selected, 276 bees were caught on Camassia, and 53 were caught on C. scoparius. Of the bees in our focal species caught on Camassia, 83 were $A$. mellifera, 70 were B. melanopygus, 79 were $B$. mixtus, and 36 were $B$. vosnesenskii. Of the bees caught on $C$. scoparius, 15 were A. mellifera, 34 were $B$. melanopygus, seven were $B$. mixtus, and two were $B$. vosnesenskii.

\section{Bees caught on Camassia}

Focal bee species differed in the ratio of C. scoparius to Camassia pollen on their bodies $(F(3,268)=95.9, P<0.001)$, with A. mellifera having the lowest amount of $C$. scoparius relative to Camassia pollen, B. vosnesenskii and B. mixtus being intermediate and $B$. melanopygus having the most. Body pollen was not affected by any other variable.

For pollen collected from the corbiculae there was a significant interaction between bee species and $C$. scoparius density $\left(\chi_{3,177}^{2}=19.51, P=0.0002\right.$; Fig. 1), as well as an overall effect of species $\left(\chi_{3, \quad 177}^{2}=28.64, \quad P<0.001\right)$. Not only did $B$. melanopygus have more C. scoparius pollen, but the relative quantity of $C$. scoparius in the corbiculae increased more strongly with $C$. scoparius density than it did for other bee species (Fig. 1). Finally, bees collected from the different Camassia species differed in the ratio of $C$. scoparius to Camassia pollen, with those from $C$. leichtlinii having more C. scoparius pollen $\left(\chi_{3,177}^{2}=7.43, P=0.006\right)$.

\section{Bees caught on Camassia scoparius}

Bees collected on C. scoparius generally had a high relative quantity of $C$. scoparius pollen on
Fig. 1. Pollen composition on different bee species changes differently with increases in Cytisus scoparius density.

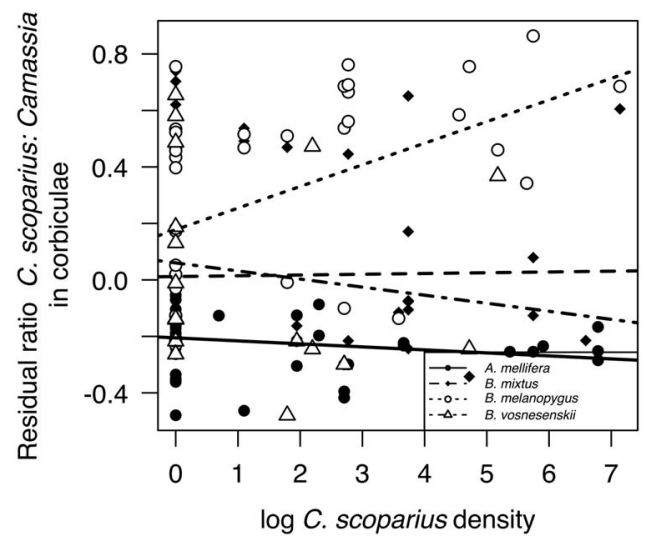

their body and in their corbiculae (corbiculae composition average $=0.96$, body $=0.97$ ) Although only seven individuals of $B$. mixtus were caught, when considering this species alone a relatively high proportion did not have pure pollen loads, in contrast to A. mellifera and B. melanopygus (Fig. 2).

\section{Cystisus scoparius tripping}

Cystisus scoparius floral tripping declined with both sampling date $\left(\chi_{1,123}^{2}=13.45, P<0.001\right.$; Fig. 3A) and C. scoparius density $\left(\chi_{1,123}^{2}=9.16\right.$, $P=0.002$; Fig. 3B). Measurements of intertegular span show that B. melanopygus is the largest of our sampled bees $(3.71 \pm 0.06 \mathrm{~mm})$, followed by $B$. mixtus $(3.22 \pm 0.06 \mathrm{~mm})$, B. vosnesenskii $(3.38 \pm 0.1 \mathrm{~mm})$, and A. mellifera $(2.92 \pm 0.03 \mathrm{~mm})$.

\section{Discussion}

Bumble bee species differ in their propensity to forage on both $C$. scoparius and Camassia at the same time. Bombus melanopygus had a higher ratio of $C$. scoparius to Camassia pollen on their body when collected on Camassia, and the quantity that they collected into their corbiculae increased with density. This suggests that $B$. melanopygus is not only more willing to forage on C. scoparius than our other focal species, but that it is more likely to collect $C$. scoparius pollen for 
Fig. 2. Pollen composition on Cytisus scoparius collected bees (white = pure C. scoparius; grey = mixed pollen load).
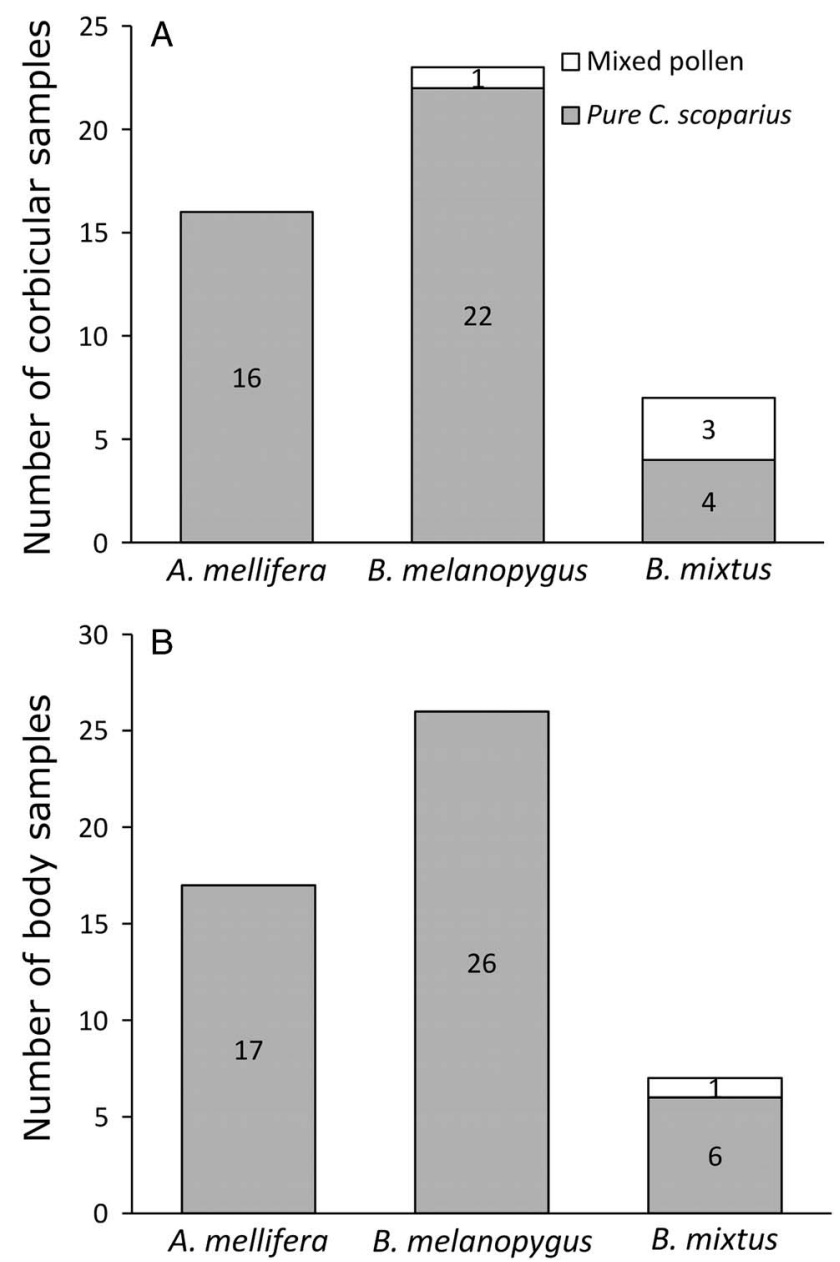

nest provisions, even while also foraging on native Camassia species. If $B$. melanopygus can use $C$. scoparius as a resource, it may be more successful at invaded sites than other pollinators. Conversely, B. mixtus and B. vosnesenskii, and the introduced $A$. mellifera, were more moderate in their inclusion of $C$. scoparius and showed no increase in $C$. scoparius pollen collection with C. scoparius density. Furthermore, all three species were caught on $C$. scoparius in lower numbers than $B$. melanopygus across our sites (Fig. 2). Thus they may be more negatively affected if $C$. scoparius displaces native plants.

Bee traits may in part explain the variation between bee species in $C$. scoparius pollen collection. While B. melanopygus tongue length is on average intermediate to $B$. mixtus and B. vosnesenskii (Harmon-Threatt and Ackerly 2013), measurements of our collected bees show that B. melanopygus workers are the largest among our focal species based on intertegular span (Cane 1987). Contrary to expectation, previous work shows that smaller bees may be more adept at handling untripped broom flowers (Stout 2000); however, that paper grouped workers and queens across coarse size categories $(<15-\mathrm{mm}$ long, 15-20-mm long, $>20-\mathrm{mm}$ long) that are difficult to compare with our measure of body size. Our study focusses only on workers, and examines more fine-scale differences across our 
Fig. 3. Changes in average Cytisus scoparius tripping levels (indicative of a pollinator visit) with: (A) C. scoparius density and (B) sampling date.
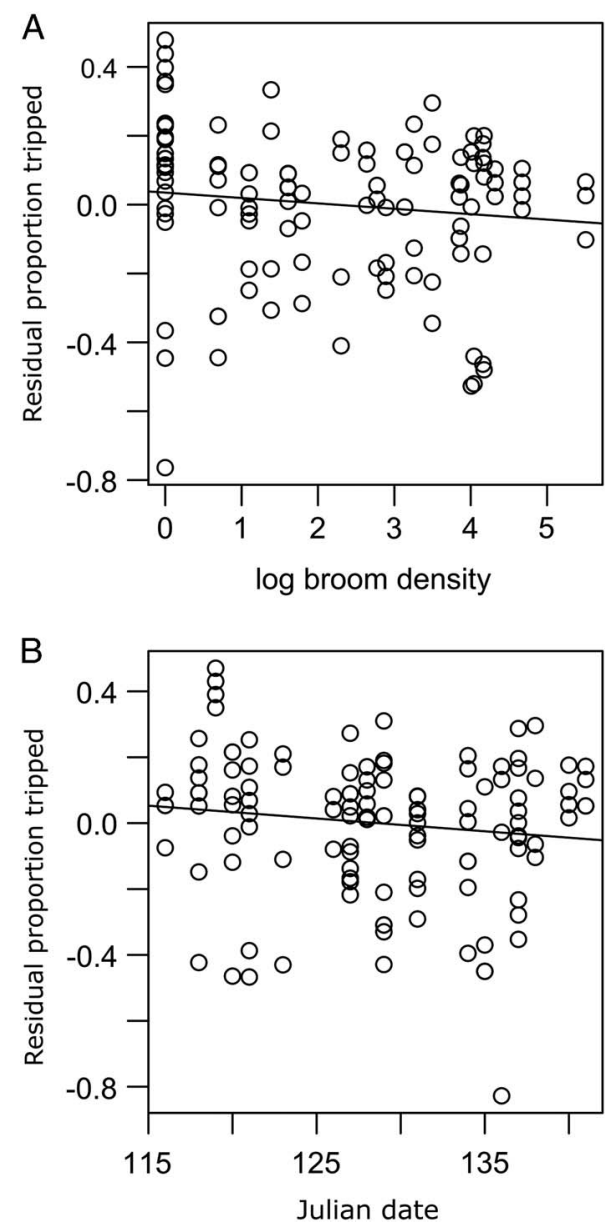

three focal bumble bee species. Our observations also suggest that honey bees appear to expend more energy using their metathoracic legs to pry open untripped flowers, whereas the weight of a bumble bee seems to trip flowers with no prying necessary (S.D.G., personal observation). Alternately, B. melanopygus may be outcompeted for pollen on Camassia. Camassia density is negatively related to $C$. scoparius density at our sites (slope $=-0.3 ; \mathrm{df}=1 ; P<0.0001 ;$ Fig. 4). As Camassia decreases in density, competition for resources from Camassia may increase, causing $B$. melanopygus to move on to less easily accessed, but less exploited resources such as C. scoparius, while returning to Camassia for nectar.
Fig. 4. Correlation between Cystisus scoparius and Camassia density.

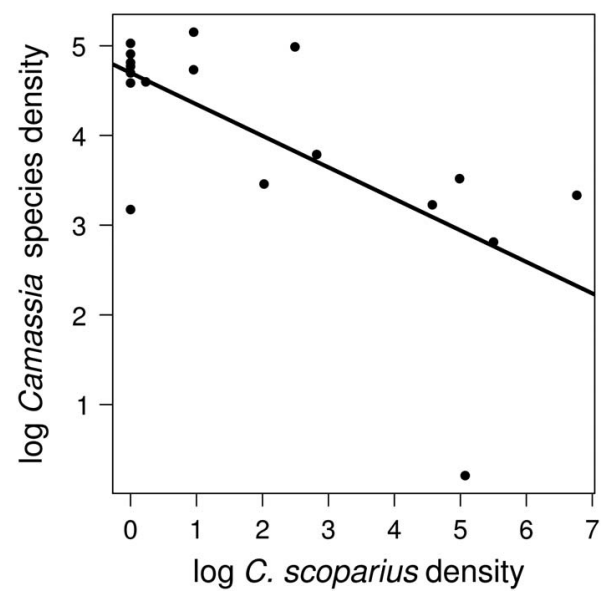

Our results provide mixed evidence that nonnative A. mellifera are facilitating pollination of C. scoparius. Apis mellifera caught on Camassia were collecting primarily Camassia pollen (Fig. 1), whereas those caught on C. scoparius were collecting primarily $C$. scoparius pollen (Fig. 2). Apis mellifera caught on Camassia did not increase collection of $C$. scoparius pollen with increasing $C$. scoparius density, and generally showed the lowest amount of $C$. scoparius pollen among our focal bee species collected on Camassia. While their constancy likely makes A. mellifera reliable pollinators of both native and invasive plants, our results suggest that at low plant densities, B. melanopygus and other native pollinators more readily forage on $C$. scoparius. An invasive plant such as $C$. scoparius with a specialised pollination syndrome can thus co-opt local pollinators, particularly those that are synonymous with pollinators in the native habitat of the plant. Cytisus scoparius is primarily pollinated by bumble bees in the native range of this species in Europe (Parker 1997), whereas in Australia, where there are no native bumble bees, it relies on introduced $A$. mellifera for pollination (Sheppard et al. 2002; Simpson et al. 2005). Because there is already a diverse community of Bombus in North America, C. scoparius does not rely on honey bees for pollination here, unlike in Australia.

Our data suggest that pollination of $C$. scoparius will change with its density; however results from pollen composition on bees versus tripping rates 
suggest different effects. Cytisus scoparius pollen on bees increases with $C$. scoparius density - but only for B. melanopygus. Conversely $C$. scoparius tripping rates actually decline with $C$. scoparius density - suggesting some density-dependent negative impacts on pollination. This could occur if there is saturation of the segment of the pollinator community that is willing to forage on C. scoparius. Alternately, our data show that high density of $C$. scoparius is associated with reduced density of native plants such as Camassia (see also Fuchs 2004). Reduction in plant abundance and diversity can result in reduced abundance or diversity of pollinators (Neame et al. 2013). Alternately, bees may be less attracted to areas with a lack of nectar resources, and may thus forage elsewhere.

Our results may have implications for plant pollination. Pollinator-dependent invasive plants can have negative impacts on natives when they are more attractive than natives (Brown et al. 2002), but also indirectly through heterospecific pollen transfer (Caruso and Alfaro 2000; Brown et al. 2002). Heterospecific transfer occurs when bees visit more than one plant species, and can negatively affect seed set either by displacing conspecific pollen (Larson et al. 2006) or via allelopathic effects on conspecific pollen germination (Murphy and Aarssen 1995). For native Camassia species, we find that $B$. melanopygus may be the biggest culprit in heterospecific transfer of $C$. scoparius pollen at sites with high C. scoparius density. Our data also show that different Camassia species may experience different indirect effects from $C$. scoparius. Bees collected from Camassia leichtlinii had significantly more $C$. scoparius pollen on them than bees collected from C. quamash. There may be more temporal overlap in the bloom times of C. leichtlinii and C. scoparius (Vamosi et al. 2014), thus bees foraging on $C$. leichtlinii may be more likely to have opportunities to forage on C. scoparius as well. This does not necessarily indicate that $C$. leichtlinii will suffer negative effects of heterospecific pollen transfer; past studies in this system show no evidence for such effects (Muir and Vamosi 2015).

Overall we find that native bumble bee species vary in their collection of invasive pollen for nest provisions. Larger bodied species such as B. melanopygus were more likely to forage on
C. scoparius, and increase use of $C$. scoparius pollen with the density of the plant. Tripping rates, an indication of pollination service to C. scoparius, decline with C. scoparius density, suggesting that saturation of local pollinators, or other community level impacts, may occur at higher densities. Non-native A. mellifera is likely not playing a major role in facilitating spread of C. scoparius. Rather C. scoparius is visited by a complement of native bumble bees that are functionally equivalent to its pollinators in the native range of the plant.

\section{Acknowledgements}

The authors are grateful to Severin Vallaincourt for field assistance; the cities of Oak Bay, Victoria, and Esquimalt, the District of Saanich, the Capital Regional District, and the National Research Council of Canada for site access; and Simon Fraser University and the Natural Sciences and Engineering Research Council (NSERC) of Canada for funding (Discovery Grant to E.E. and Undergraduate Student Research Award to J.B.).

\section{Supplementary material}

To view supplementary material for this article, please visit https://doi.org/10.4039/tce.2016.67

\section{References}

Aizen, M.A., Morales, C.L., and Morales, J.M. 2008. Invasive mutualists erode native pollination webs. Public Library of Science Biology, 6: 396-403. https://doi.org/10.1371/journal.pbio.0060031.

Bates, D., Maechler, M., Bolker, B.M., and Walker, S. 2015. Fitting linear mixed-effects models using lme4. Journal of Statistical Software, 67: 1-48. https://doi.org/10.18637/jss.v067.i01.

Brown, B.J., Mitchell, R.J., and Graham, S.A. 2002. Competition for pollination between an invasive species (purple loosestrife) and a native congener. Ecology, 83: 2328-2336. https://doi.org/10.2307/ 3072063 .

Cane, J.H. 1987. Estimation of bee size using intertegular span (Apoidea). Journal of the Kansas Entomological Society, 60: 145-147.

Caruso, C.M. and Alfaro, M. 2000. Interspecific pollen transfer as a mechanism of competition: effect of Castilleja linariaefolia pollen on seed set of Ipomopsis aggregata. Canadian Journal of Botany, 78: $600-606$. 
Chamberlain, S.A., Cartar, R.V., Worley, A.C., Semmler, S.J., Gielens, G., Elwell, S., et al. 2014. Traits and phylogenetic history contribute to network structure across Canadian plant-pollinator communities. Oecologia, 176: 545-556. https://doi.org/ 10.1007/s00442-014-3035-2.

Fuchs, M. 2004. Towards a recovery strategy for Garry oak and associated ecosystems in Canada: ecological assessment and literature review. Technical Report GBEI/EC-00-030. Environment Canada, Canadian Wildlife Service, Pacific and Yukon Region, Delta, British Columbia, Canada.

Goulson, D. and Darvill, B. 2004. Niche overlap and diet breadth in bumblebees; are rare species more specialized in their choice of flowers? Apidologie, 35: 55-63. https://doi.org/10.1051/apido:2003062.

Harmon-Threatt, A.N. and Ackerly, D.D. 2013. Filtering across spatial scales: phylogeny, biogeography and community structure in bumble bees. Public Library of Science One, 8: e60446. https:// doi.org/10.1371/journal.pone.0060446.

Harmon-Threatt, A.N. and Kremen, C. 2015. Bumble bees selectively use native and exotic species to maintain nutritional intake across highly variable and invaded local floral resource pools. Ecological Entomology, 40: 471-478. https://doi.org/10.1111/ een. 12211 .

Inouye, D.W. 1980. The effect of proboscis and corolla tube lengths on patterns and rates of flower visitation by bumblebees. Oecologia, 45: 197-201. https://doi. org/10.1007/bf00346460.

Johnson, S.D. and Raguso, R.A. 2016. The longtongued hawkmoth pollinator niche for native and invasive plants in Africa. Annals of Botany, 117: 25-36. https://doi.org/10.1093/aob/mcv137.

Kearns, C.A. and Inouye, D.W. 1993. Techniques for pollination biologists. Univerisity Press of Colorado, Niwot, Colorado, United States of America.

King, V.M. and Sargent, R.D. 2012. Presence of an invasive plant species alters pollinator visitation to a native. Biological Invasions, 14: 1809-1818. https://doi.org/10.1007/s10530-012-0191-3.

Kunin, W.E. 1993. Sex and the single mustard: population density and pollinator behavior effects on seed-set. Ecology, 74: 2145-2160. https://doi. org/10.2307/1940859.

Larson, D.L., Royer, R.A., and Royer, M.R. 2006. Insect visitation and pollen deposition in an invaded prairie plant community. Biological Conservation, 130: 148159. https://doi.org/10.1016/j.biocon.2005.12.009.

Montesinos, D., Castro, S., and Rodriguez-Echeverria, S. 2016. Two invasive acacia species secure generalist pollinators in invaded communities. Acta OecologicaInternational Journal of Ecology, 74: 46-55. https:// doi.org/10.1016/j.actao.2016.06.002.

Morales, C.L. and Aizen, M.A. 2006. Invasive mutualisms and the structure of plant-pollinator interactions in the temperate forests of north-west Patagonia, Argentina. Journal of Ecology, 94: 171-180.
Muir, J.L. and Vamosi, J.C. 2015. Invasive Scotch broom (Cytisus scoparius, Fabaceae) and the pollination success of three Garry oak-associated plant species. Biological Invasions, 17: 2429-2446. https://doi.org/10.1007/s10530-015-0886-3.

Murphy, S.D. and Aarssen, L.W. 1995. Reduced seed set in Elytrigia repens caused by allelopathic pollen from Phleum pratense. Canadian Journal of Botany, 73: 1417-1422.

Neame, L.A., Griswold, T., and Elle, E. 2013. Pollinator nesting guilds respond differently to urban habitat fragmentation in an oak-savannah ecosystem. Insect Conservation and Diversity, 6: 57-66. https://doi.org/10.1111/j.1752-4598.2012.00187.x.

Parker, I.M. 1997. Pollinator limitation of Cytisus scoparius (Scotch broom), an invasive exotic shrub. Ecology, 78: 1457-1470.

Paynter, Q., Main, A., Gourlay, A.H., Peterson, P.G., Fowler, S.V., and Buckley, Y.M. 2010. Disruption of an exotic mutualism can improve management of an invasive plant: varroa mite, honeybees and biological control of Scotch broom Cytisus scoparius in New Zealand. Journal of Applied Ecology, 47: 309-317. https://doi.org/10.1111/j.1365-2664.2010.01784.x.

Peat, J., Tucker, J., and Goulson, D. 2005. Does intraspecific size variation in bumblebees allow colonies to efficiently exploit different flowers? Ecological Entomology, 30: 176-181. https://doi. org/10.1111/j.0307-6946.2005.00676.x.

Pysek, P., Jarosik, V., Chytry, M., Danihelka, J., Kuhn, I., Pergl, J., et al. 2011. Successful invaders co-opt pollinators of native flora and accumulate insect pollinators with increasing residence time. Ecological Monographs, 81: 277-293. https://doi. org/10.1890/10-0630.1.

Pysek, P., Jarosik, V., Hulme, P.E., Pergl, J., Hejda, M., Schaffner, U., and Vila, M. 2012. A global assessment of invasive plant impacts on resident species, communities and ecosystems: the interaction of impact measures, invading species' traits and environment. Global Change Biology, 18: 1725-1737. https://doi.org/10.1111/j.1365-2486.2011.02636.x.

R Development Core Team. 2009. R: a language and environment fo statistical computing. R Foundation for Statistical Computing, Vienna, Austria.

Shaben, J. and Myers, J.H. 2010. Relationships between Scotch broom (Cytisus scoparius), soil nutrients, and plant diversity in the Garry oak savannah ecosystem. Plant Ecology, 207: 81-91. https://doi.org/10.1007/s11258-009-9655-7.

Sheppard, A.W., Hodge, P., Paynter, Q., and Rees, M. 2002. Factors affecting invasion and persistence of broom Cytisus scoparius in Australia. Journal of Applied Ecology, 39: 721-734. https://doi.org/ 10.1046/j.1365-2664.2002.00750.x.

Simpson, S.R., Gross, C.L., and Silberbauer, L.X. 2005. Broom and honeybees in Australia: an alien liaison. Plant Biology, 7: 541-548. https://doi.org/ $10.1055 / \mathrm{s}-2005-865855$. 
Stout, J.C. 2000. Does size matter? Bumblebee behaviour and the pollination of Cytisus scoparius L. (Fabaceae). Apidologie, 31: 129-139.

Stout, J.C., Kells, A.R., and Goulson, D. 2002. Pollination of the invasive exotic shrub Lupinus arboreus (Fabaceae) by introduced bees in Tasmania. Biological Conservation, 106: 425-434. https://doi. org/10.1016/s0006-3207(02)00046-0.

Traveset, A. and Richardson, D.M. 2006. Biological invasions as disruptors of plant reproductive mutualisms. Trends in Ecology \& Evolution, 21: 208-216. https://doi.org/10.1016/j.tree.2006.01.006.

Traveset, A. and Richardson, D.M. 2014. Mutualistic interactions and biological invasions. Annual Review of Ecology, Evolution, and Systematics, 45: 89-113.
Vamosi, J.C., Moray, C.M., Garcha, N.K., Chamberlain, S.A., and Mooers, A.O. 2014. Pollinators visit related plant species across 29 plant-pollinator networks. Ecology and Evolution, 4: 2303-2315. https://doi.org/10.1002/ece3.1051.

Vaudo, A.D., Patch, H.M., Mortensen, D.A., Tooker, J.F., and Grozinger, C.M. 2016. Macronutrient ratios in pollen shape bumble bee (Bombus impatiens) foraging strategies and floral preferences. Proceedings of the National Academy of Sciences of the United States of America, 113: E4035-E4042. https://doi.org/10.1073/ pnas. 1606101113. 